\title{
Cyanide Containing Wastewater Treatment by Ozone Enhanced Catalytic Oxidation over Diatomite Catalysts
}

\author{
Mingguo Lin ${ }^{1}$, Qiyuan $\mathrm{Gu}^{2}$, Xinglan $\mathrm{Cui}^{2}$ and Xingyu $\mathrm{Liu}^{2 *}$ \\ ${ }^{1}$ Liaoning Xindu Gold Co., Ltd, 122000 Chaoyang, China \\ ${ }^{2}$ General Research Institute for Nonferrous Metals Engineering, National Engineering Laboratory of \\ Biohydrometallury, 100088 Beijing, China \\ The first two authors contributed equally to this paper
}

\begin{abstract}
Cyanide containing wastewater that discharged from gold mining process creates environmental problems due to the toxicity of cyanide. As one of the promising advanced oxidation process, catalytic oxidation with ozone is considered to be effective on the purification of cyanide. Diatomite, a natural mineral, was used as catalyst in this study. The effect of $\mathrm{O}_{3}$ dosage, salinity, initial cyanide concentration and initial $\mathrm{pH}$ condition were investigated. It was observed that the removal rate of cyanide was much higher in the catalytic oxidation with ozone process than the one in zone alone process. Alkaline condition was especially favorable for cyanide in catalytic oxidation with ozone. The ozone and catalytic oxidation with ozone were simulated by pseudo-first-order kinetics model. The apparent first-order rate constant contribution of the diatomite catalyst was $0.0757 \mathrm{~min}^{-1}$, and the contribution percentage was $65.77 \%$.
\end{abstract}

\section{Introduction}

Cyanidation is the most popular process by which gold is recovered from the ores in mining operations. The aqueous cyanide solution which is used to dissolution of gold is typically carried out with $0.03-0.3 \% \mathrm{NaCN}$ [1]. The cyanide in the solution is used as complexing agent. However, after extraction and recovery of gold, the drainage containing large amounts of cyanide need be discharged, which create environmental problems due to the toxicity of cyanides [2].

The cyanide could present three forms in wastewater, including free cyanide, simplex cyanide and complex cyanide. For the widespread use of cyanide in gold mining operation, the purification of cyanide is important. Both treatment efficiency and cost could be considered [3]. The Ministry of Environmental Protection of the People's Republic of China has proposed a discharge limit of $0.5 \mathrm{mg} / \mathrm{L}$ cyanide for sewers. And in Liaoning Province, the limit for cyanide is $0.2 \mathrm{mg} / \mathrm{L}$. For meeting the strict discharge standard requirement, several cyanide treatment processes have been developed.

\footnotetext{
* Corresponding author: wellwoodliu@163.com
} 
Catalytic oxidation with ozone is one of the promising treatment techniques for cyanide removal. Ozone has been demonstrated to be effective on the purification of nonbiodegradable compounds, by the way of direct oxidation with $\mathrm{O}_{3}$ and the indirect way with hydroxyl radicals [4].

In the last years, the combined use of $\mathrm{O}_{3}$ and activated carbon has been developed [5]. The treatment efficiency was enhanced dramatically by using activated carbon as catalyst [6]. Unfortunately, the cost of activated carbon is expensive, which is limited the application of the combined process. Diatomite could be the substitute catalyst which has porous structure and high surface area. In this study, the operating parameter of combined $\mathrm{O}_{3}$ and diatomite were optimized.

\section{Materials and methods}

\subsection{Wastewater}

The real cyanide containing wastewater was captured from a gold mine company in Liaoning Province. The cyanide concentration is $15 \sim 20 \mathrm{mg} / \mathrm{L}$, and COD concentration is 150 200 mg/L.

\subsection{Analyses}

The concentrations of cyanide were measured by using an ion selection electrode. COD was measured according to standard methods. The microstructure of diatomite was observed by scanning electron mircroscope (ZEISS EVO 18). The increase in apparent rate constant (pseudo-first-order) $\mathrm{K}_{\text {app }}$ resulted from adding diatomite during the ozone process can be used to indicate the contribution and contribution percentage of effect of diatomite catalyst, which was calculated as the following equation:

$$
\text { Contribution } K_{a p p}=K_{a p p}(\text { with diatomite })-K_{a p p}(\text { without diatomite })
$$

Contribution percentage $=\left(1-K_{\text {app }}(\right.$ without diatomite $) / K_{\text {app }}($ with diatomite $) \times 100 \%$

The pseudo-first-order kinetics of both processes was simulated as:

$$
\operatorname{In}\left(C_{0} / C\right)=K_{a p p} t
$$

Where $\mathrm{C}$ is the cyanide concentration at time $\mathrm{t}, \mathrm{C}_{0}$ is the initial cyanide concentration, and $\mathrm{K}_{\mathrm{app}}$ is the apparent first-order rate constant.

\subsection{Experimental method}

The schematic diagram of combined ozone and diatomite system is shown in Fig.1. Two parallel set of ozone reactor, named R1 and R2, were operated concurrently. R2 was similar with R1 except adding diatomite. R1 and R2 reactor were made by borosilicate glass. Ozone was continuously added to the reactor. 


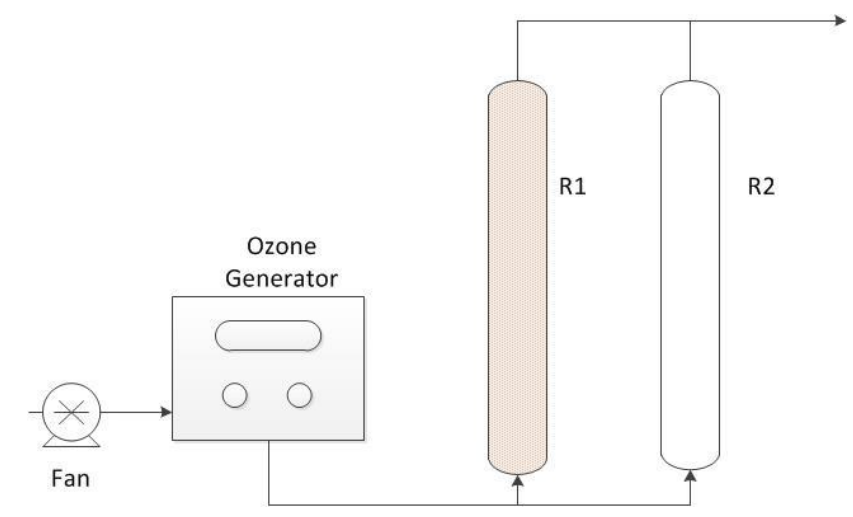

Fig. 1. Schematic diagram of combined ozone and diatomite system.

\section{Results and discussion}

\subsection{Micro-morphology observation of diatomite}

The electronic micrograph of diatomite was shown in Fig. 2. The diatomite has high porosity which could provide the site to promote the reaction between $\mathrm{O}_{3}$ and cyanide.

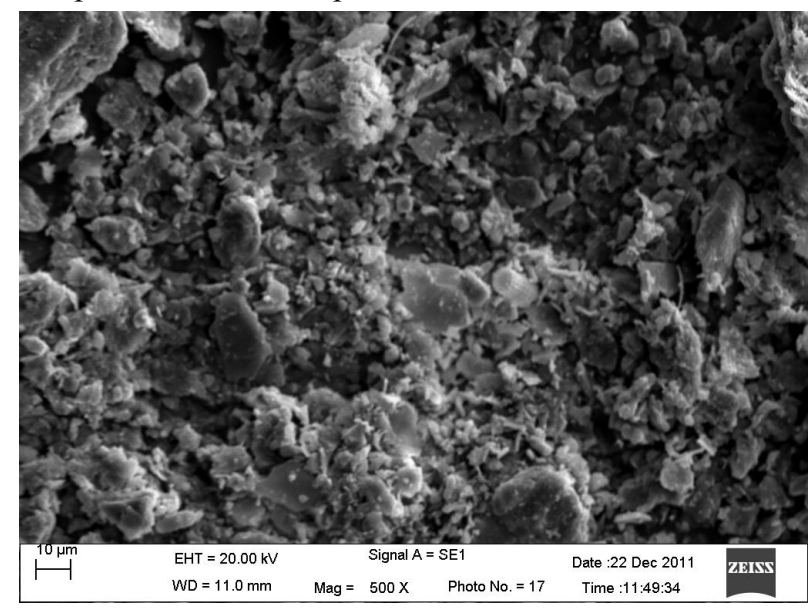

Fig. 2. Scanning electron micrographs for diatomite.

\subsection{Effect of $\mathrm{O}_{3}$ dosage}

Fig. 3 shows the cyanide concentration as a function of $\mathrm{O}_{3}$ dosage. The results indicated the combined $\mathrm{O}_{3}$ and diatomite process presented better cyanide purification performance than the $\mathrm{O}_{3}$ alone process. Cyanide concentration in $\mathrm{R} 1$ decreased from $15.8 \mathrm{mg} / \mathrm{L}$ to $0.1 \mathrm{mg} / \mathrm{L}$ with an increase in the $\mathrm{O}_{3}$ dosage to $16 \mathrm{mg} / \mathrm{L}$, while the cyanide concentration in $\mathrm{R} 2$ dropped to $6.3 \mathrm{mg} / \mathrm{L}$. 


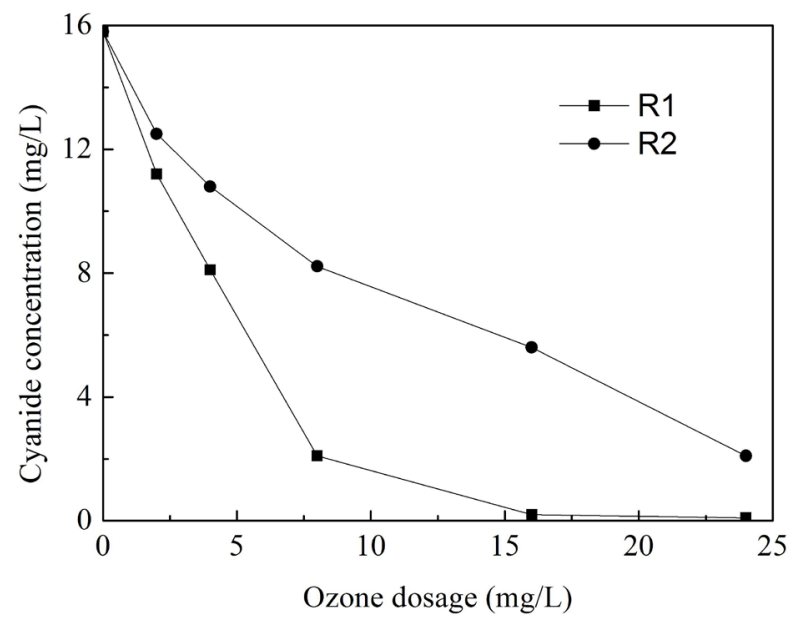

Fig. 3. Effect of $\mathrm{O}_{3}$ dosage on the removal of cyanide.

\subsection{Effect of salinity}

Salinity always influences the catalytic oxidation via the competitive adsorption of inorganic anions on catalyst sites. The influence of $\mathrm{NaCl}$ was investigated during catalytic oxidation with ozone. The effect of $\mathrm{NaCl}$ is shown in Fig. 4, in which a series amount of $\mathrm{NaCl}(0,0.5 \mathrm{~g} / \mathrm{L}, 1 \mathrm{~g} / \mathrm{L})$ was added in the oxidation system. It is observed that the salinity did not influence the catalytic oxidation significantly. The real industrial wastewater always contains high salinity. The results indicated that the catalytic oxidation with ozone process could be suitable for the treatment of industrial wastewater.

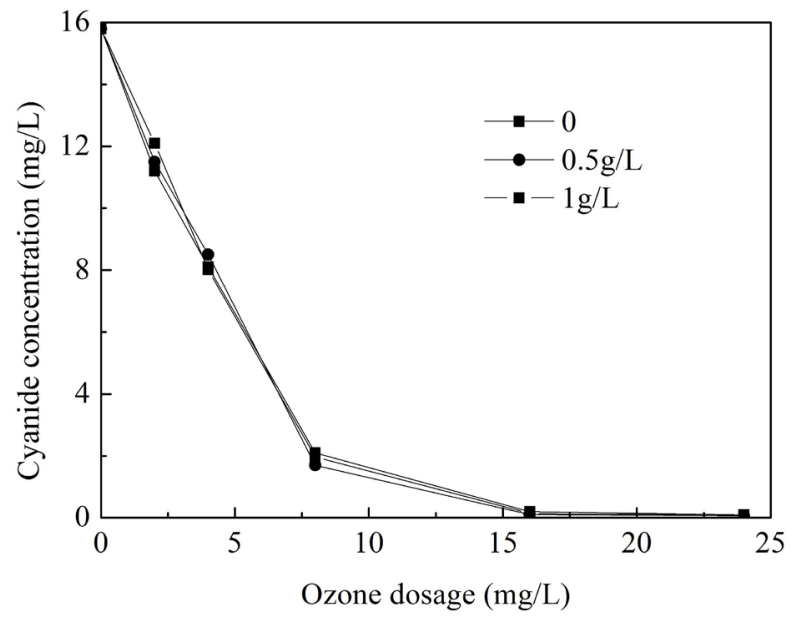

Fig. 4. Effect of salinity on the removal of cyanide.

\subsection{Effect of initial pH}


Cyanide containing wastewater could influence the charge property of cyanide and removal efficiency of ozone process. The effect of cyanide containing wastewater $\mathrm{pH}$ on the treating rate was investigated from 5.0 to 9.0. As illustrated in Fig.5, the fastest cyanide removal rate was observed in the condition of $\mathrm{pH} 9.0$, while the slowest was demonstrated in the condition of $\mathrm{pH}$ 5.0. The acid solution condition could not promote the reaction activity between $\mathrm{O} 3$ and cyanide. These observation also indicated that at high $\mathrm{pH}$ the hydroxyl radical could be the predominant oxidant for the cyanide. The product of cyanide oxidation is cyanate, which occurs according to $\mathrm{Eq}(4)$ :

$$
\mathrm{CN}^{-}+\mathrm{O}_{3} \rightarrow \mathrm{CNO}^{-}+\mathrm{O}_{2}
$$

In the mostly alkaline solutions hydrolysis of $\mathrm{CNO}^{-}$is also possible:

$$
\mathrm{CNO}^{-}+\mathrm{OH}^{-}+\mathrm{H}_{2} \mathrm{O} \rightarrow \mathrm{CO}_{3}^{2-}+\mathrm{NH}_{3}
$$

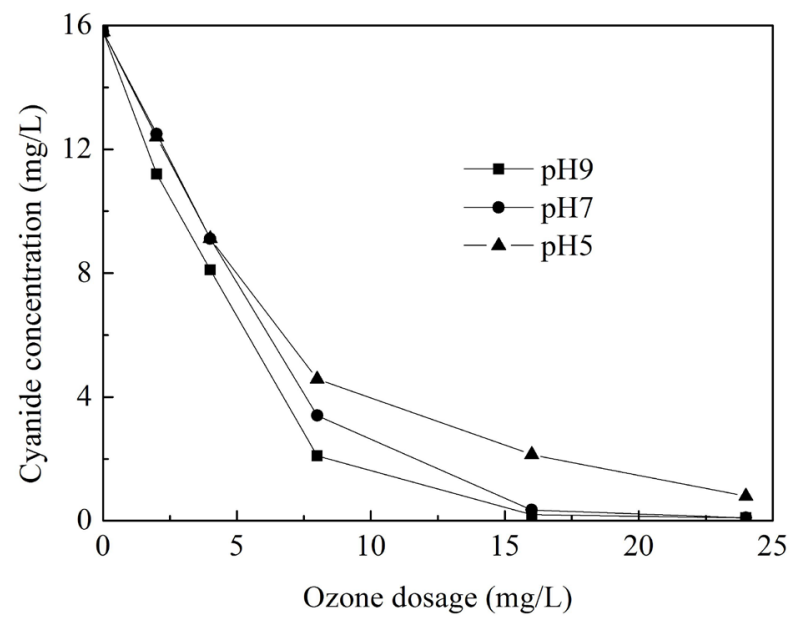

Fig. 5. Effect of $\mathrm{pH}$ on the removal of cyanide.

\subsection{Effect of initial cyanide concentration}

The tests of difference initial cyanide concentrations were carried out (Fig. 6). When the initial cyanide concentration was $15.8 \mathrm{mg} / \mathrm{L}, 16 \mathrm{mg} / \mathrm{L} \mathrm{O} 3$ was needed to add into the solution. The initial cyanide removal rate decreased with the drop of the initial cyanide concentration. High initial cyanide concentration could promote the oxidation reaction. The increased initial cyanide concentration provided more drive force to transfer cyanide to diatomite surface. Therefore, the hydroxyl radicals generated by ozone could react with more cyanide. 


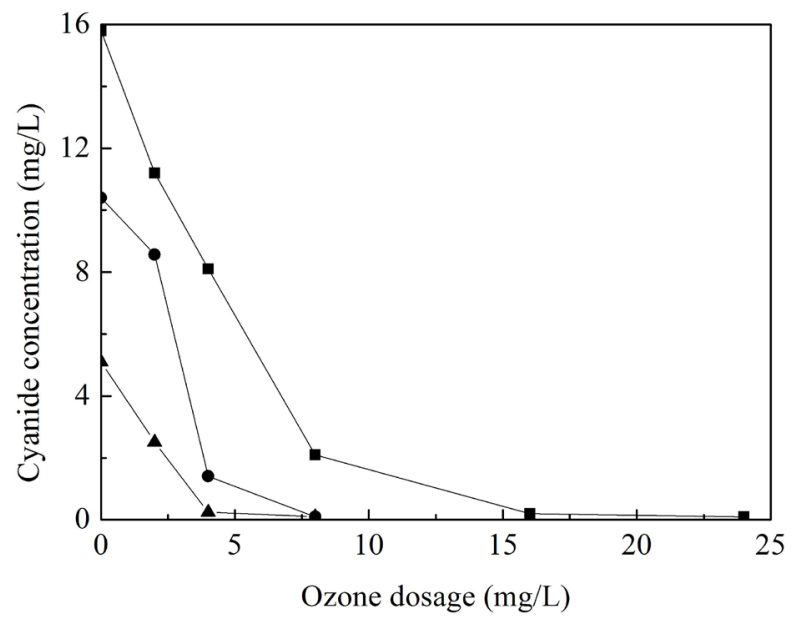

Fig. 6. Effect of initial concentration on the removal of cyanide.

\subsection{Kinetics analysis}

The pseudo-first-order kinetics was used to simulate the cyanide degradation data. Fig.7(a) shows the change trend of cyanide removal efficiency vs time. The apparent first-order rate constants of cyanide oxidation were determined from the slope of the straight lines obtained by plotting the ratios of the remaining concentration to the initial concentration on logarithmic scale. As shown in the Fig. 7(b), the data could fit the pseudo-first-order kinetics model very well. It is also evident from Fig. 7(b), that the behavior of cyanide oxidation identified a pseudo-first-order reaction with respect to cyanide concentration in solution. The apparent first-order rate constant of the ozone oxidation without diatomite is 0.0394 min-1, and regression R2 is $98.41 \%$, while the one with diatomite is 0.1151 and $98.07 \%$. The cyanide oxidation was enhanced by adding diatomite as catalyst. The catalyst of diatomite during the ozone oxidation plays a significant role during the process. The $\mathrm{K}_{\mathrm{app}}$ contribution in the present of diatomite was $0.0757 \mathrm{~min}^{-1}$, and the contribution percentage of adding diatomite was $65.77 \%$.
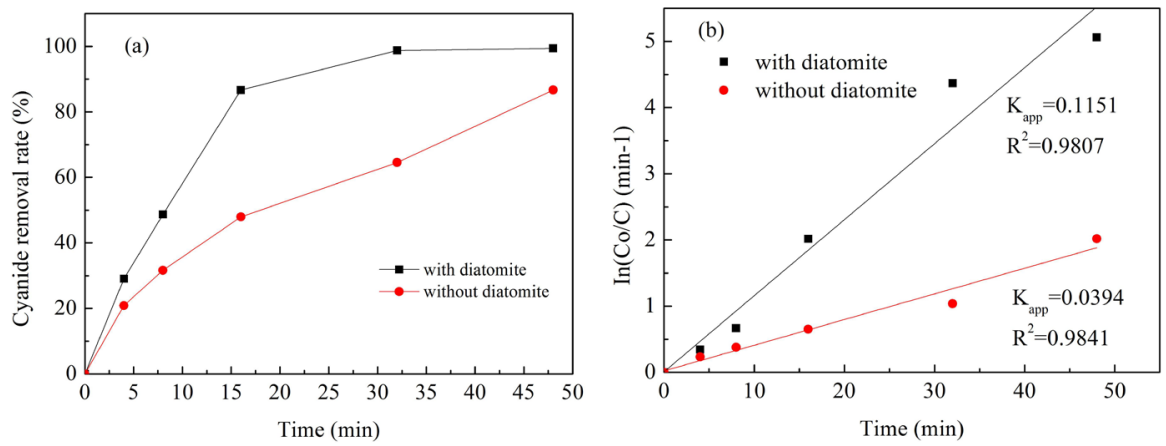

Fig. 7. Pseudo-first-order kinetics modeling: (a) trend of cyanide removal efficiency vs time, (b) correlation between experimental data (points) and prediction curves (line). 


\section{Summary}

During cyanide oxidation by catalytic oxidation with ozone, the contribution and contribution percentage of diatomite which was used as catalyst were investigated by comparison with single ozone process. The apparent first-order rate constant contribution of the diatomite catalyst was $0.0757 \mathrm{~min}^{-1}$, and the contribution percentage was $65.77 \%$. In addition, the effect study of $\mathrm{O}_{3}$ dosage, salinity, initial cyanide concentration and initial $\mathrm{pH}$ condition were carried out. It was observed that alkaline condition was especially favorable for cyanide in catalytic oxidation with ozone. And the solution salinity did not influence the catalytic oxidation effect. These results indicated that catalytic oxidation with ozone is effective on the purification of cyanide.

This work was supported by the fund of General Research Institute for Nonferrous metals under grant numbers 53321 and 53348, and the public welfare fund of the Ministry of Environmental Protection of People's Republic of China under grant number 201509049, the National Natural Science Foundation of China under grant numbers U1402234, 41573074.

\section{References}

1. J. A. Zeevalkink, D. C. Visser, P. Arnoldy, C. Boelhouwer, Wat. Res. 14, 1375 (1980)

2. J. R. Parga, D. L. Cocke, Desalination 140, 289 (2001)

3. U. Kepa, E. S. Mazanek, L. Stepniak, Desalination, 223, 187 (2008)

4. M. D. Gurol, R. Vatistas, Wat. Res. 21, 895 (1980)

5. F. R. Carrillo-Pedroza, F. Nava-Alonso, A. Uribe-Salas, Miner. Eng. 13, 541 (2000)

6. J. Cui, X. Wang, Y. Yuan, X. Guo, X. Gu, L. Jian, Chem. Eng. J. 241, 184 (2014) 